\title{
Effect of Feeding Regimens on the Functional Recovery of Pancreatic Enzymes in Postnatally Malnourished Weanling Rats
}

\author{
THOMAS M. ROSSI, PING-C. LEE, AND EMANUEL LEBENTHAL ${ }^{(33)}$ \\ Division of Gastroenterology and Nutrition, Department of Pediatrics, Children's Hospital and the State University of \\ New York, Buffalo, New York, USA
}

\begin{abstract}
Summary
Malnutrition was induced in the immediate postnatal period by expanding newborn litters to 20 rat pups/dam. The reversibility of the effects of malnutrition on the pancreas was evaluated by comparing two different feeding methods. At 21 days of age, pups from the expanded litters exhibited significantly decreased body $(P<0.0005)$ and pancreatic $(P<0.0025)$ weights as compared to those from control litters (12 pups/dam). Malnourished pups also had less contents of amylase $(P<0.01)$, lipase $(P<0.0005)$ and trypsinogen $(P<0.0025)$ in their pancreases. The concentrations (specific activities) of amylase $(P<0.05)$ and lipase $(P<0.0125)$ were significantly decreased but trypsinogen $(P<0.35)$ was not affected.

Subsequent nutritional rehabilitation by an ad libitum (food available $24 \mathrm{~h} /$ day) or restricted (food available $2 \mathrm{~h} /$ day) feeding regimen failed to allow for "catch-up" in body $(P<0.025)$ and pancreatic weight $(P<0.05)$ by 56 days of life. With ad libitum feedings, enzyme contents and concentrations of amylase and lipase in malnourished animals attained control values by 7 and 14 days, respectively. Restricted feedings, however, delayed the recovery in amylase by an additional 7 days but lipase remained depressed in both content, $(P<0.005)$ and specific activity $(P<$ $0.0025)$ for the duration of the experiment ( 56 days). Changes in pancreatic enzymes in response to malnutrition are readily reversible with ad libitum feedings but changes in somatic and pancreatic weights were not reversed. Restricted feedings have no advantage in promoting the rate of recovery of the pancreas after postnatal malnutrition.
\end{abstract}

Pancreatic weight and enzyme content in rats have been shown previously to be markedly reduced by malnutrition during the early postnatal period (9). Both parameters are similarly reduced in rats subjected to reduced maternofetal blood flow in utero during the third trimester (17). In either case, changes in the concentrations of the different enzymes appear to be nonparallel. The reversibility of these changes with subsequent nutritional rehabilitation has not been examined.

The frequency of feedings has been shown to influence intestinal functions. Animals subjected to restricted feeding schedules exhibit higher levels of disaccharidases $(13,26)$, higher levels of hepatic and adipose tissue enzymes involved in lipogenesis (19, $21)$, and increased absorption of glucose $(12,15,16,28)$. One preliminary report suggested that the pancreatic enzymes may also be raised (24). In addition, animals on restricted feedings exhibit hypertrophy of the stomach and small intestine allowing them to adapt to the excessive nutritional load (7). These findings indicate a more efficient absorption and metabolism of nutrients.
Reports on the weight velocities of animals on restricted feedings have yielded conflicting data. Some studies demonstrated that these animals consumed more nutrients (11) and subsequently gained weight more rapidly $(10,11)$. In another study, depressed body weight and food consumption were found in 68-day-old rats on restricted feedings as compared to their control counterparts (20) fed ad libitim. After an initial adaptation period of 1-2 wk the animals on restricted feedings, although still consuming less food, began to show a parallel rate of weight gain to that of controls (20) fed ad libitum.

The purpose of the present study was 2-fold; (1) to evaluate whether the pancreatic changes caused by postnatal malnutrition are reversible and (2) to assess if restricted feedings with its presumed acquired proficiencies will be advantageous in promoting recovery in comparison to unrestricted feeding.

\section{MATERIALS AND METHODS}

Animals and deprivation technique. An expanded litter model that we have reported in the past was used to induce postnatal malnutrition (9). Pregnant Sprague Dawley rats were obtained commercially (Charles River). Normal litters delivering within 12-16 h were redistributed such that control litters consisted of 12 pups per dam whereas experimental litters consisted of 20 pups per dam. Both control and experimental litters were maintained in the same environment with stock feeding and water given ad libitum for the first 21 days.

At 21 days of age, randomly selected pups from both groups were sacrificed by cervical dislocation. The entire pancreas was resected, weighed, and frozen at $-20^{\circ} \mathrm{C}$. Remaining pups from both control and malnourished groups were then subdivided and weaned onto an ad libitum (food available for $24 \mathrm{~h}$ ) or restricted (food available for $2 \mathrm{~h}, 0800-1000 \mathrm{~h}$ ) feeding schedule. There were four subgroups of animals: (1) control, fed ad libitum; (2) control, restricted feedings; (3) malnourished, fed ad libitum; and (4) malnourished, restricted feedings. Thereafter, at weekly intervals until 56 days of age, rats from each group were sacrificed at 8-10 a.m. after an overnight fast. Their pancreases were removed for enzyme determinations (Fig. 1).

For each individual animal its body weight, pancreatic weight, total and specific activities of trypsinogen, amylase, and lipase in the pancreatic homogenate were measured.

Preparation of pancreatic homogenate. The entire pancreas was minced, diluted with ice cold saline $(0.1 \mathrm{ml} / \mathrm{mg}$ of tissue $)$, and homogenized in a Potter-Elvehjem glass homogenizer with a teflon pestle. Individual homogenates were stored separately in microtubes at $-20^{\circ} \mathrm{C}$ until enzyme determination could be performed. Storage of homogenate was found to retain more than $90 \%$ of enzyme activities for 3-4 wk after one thawing. 
EXPERIMENTAL DESIGN
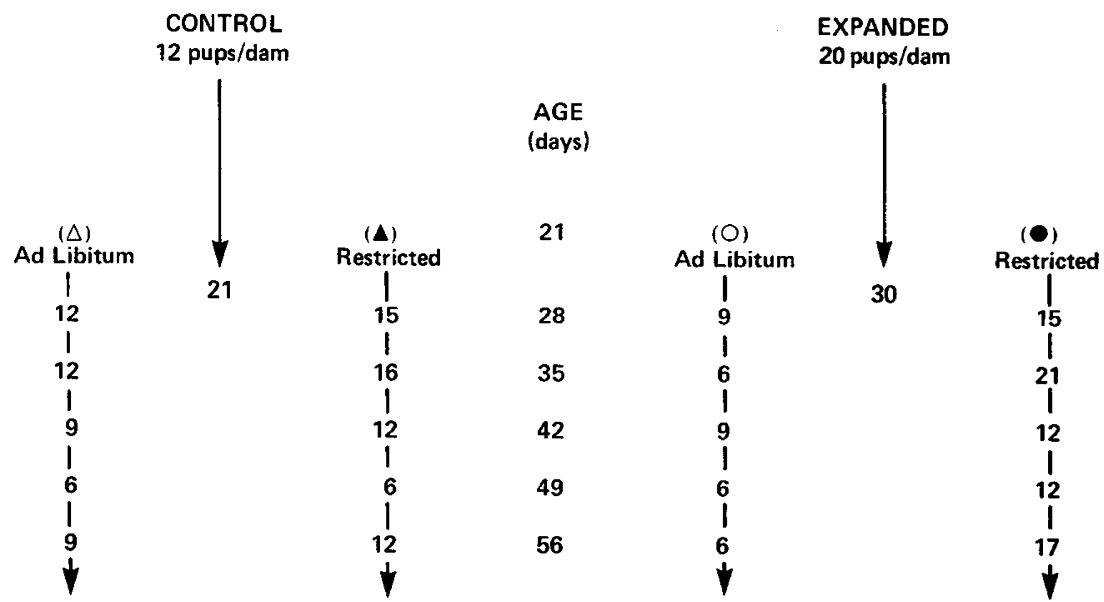

Fig. 1. Experimental design for control and expanded litters. Numbers following arrows indicate number of animals sacrificed for each age group.

Biochemical analysis. For trypsinogen determination, enterokinase was added to the homogenate and allowed to incubate so as to convert the enzyme into trypsin. Trypsin (EC 3.4.4.4) activity was then measured from the hydrolysis of $p$-nitroaniline from benzoyl-DL-arginine-p-nitroaniline at $\mathrm{pH} 8.2$ and $25^{\circ} \mathrm{C}(6,23)$. Units are expressed as nanomoles of $p$-nitroaniline released per minute per milligram of protein. $\alpha$-Amylase (EC 3.2.1.1) was determined by the saccharogenic method (25) using soluble starch as the substrate. Units are expressed as micromoles of maltose liberated per minute per mg of protein. Lipase (EC 3.1.1.3) activity was determined by the potentiometric titration (at constant $\mathrm{pH} \mathrm{8)}$ of ionized fatty acids liberated from a triglyceride (olive oil) emulsion with $0.1 \mathrm{~N} \mathrm{NaOH}$ (8). Units are expressed as micromoles of $\mathrm{NaOH}$ required to neutralize free fatty acids liberated per minute per milligram of protein. Total proteins were done according to the Lowry method using the Folin phenol reagent $(22,27)$.

Statistics. The data was analyzed by unpaired Student's $t$ tests. A value of $P<0.05$ was considered to indicate statistical significance.

\section{RESULTS}

Growth parameters. At 21 days, the mean total body weight for malnourished rats was significantly less $(P<0.0005)$ than control animals of the same age (Fig. 2). Similarly, mean pancreatic weight was also significantly diminished $(P<0.0025)$. Both body and pancreatic weights of the malnourished pups were approximately $70 \%$ of the control pups.

With subsequent nutritional rehabilitation, either ad libitum or restricted feedings, mean body and pancreatic weights increased. The gain in weights of the body and pancreas of continuously fed malnourished animals paralleled that of the continuously fed controls, but the effects of prior malnutrition were still evident (Fig. 2) at 35 days of nutritional rehabilitation (56 days of age). Rats previously malnourished still showed significantly lower body weight $(P<0.025)$ and pancreatic weight $(P<0.05)$ (Fig. $2)$. The differences in weights between malnourished and control groups were more striking in the malnourished animals on restricted feedings. At day 56, their body weights were only $52 \%$ of controls whereas the continuously fed malnourished group reached $84 \%$ of the controls.

\section{PANCREATIC ENZYMES}

Specific activities. Pups malnourished for the first 21 days after birth had significantly lower specific activities of lipase $(P<$
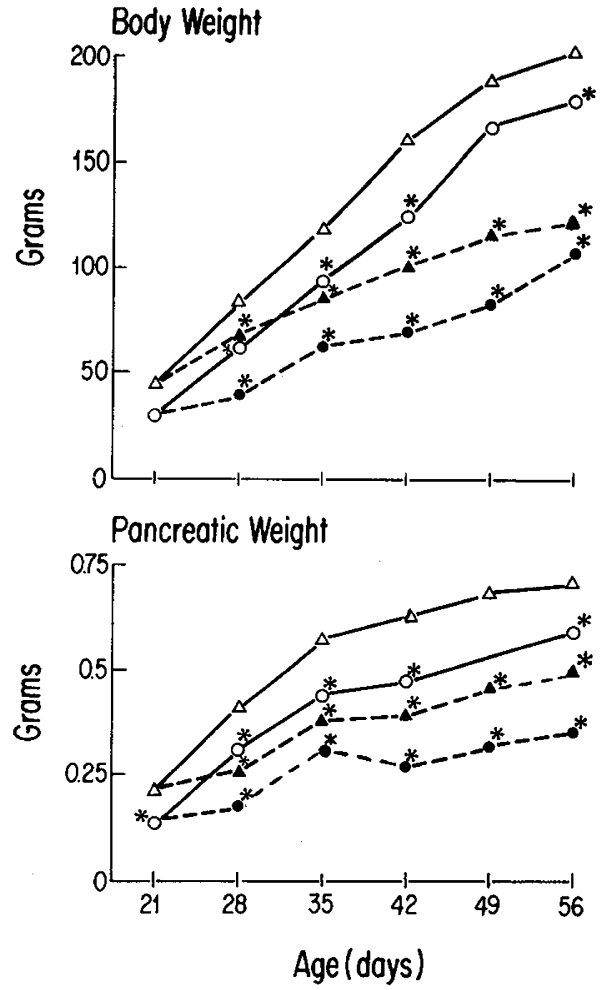

Fig. 2. Effect of postnatal malnutrition and subsequent nutritional rehabilitation by either ad libitum or restricted feedings. Symbols represent: Control, $(\triangle)$, ad libitum feedings (food available $24 \mathrm{~h}$ ) and (A), restricted feedings (food available 8-10 a.m.); malnourished, $(\mathrm{O})$, ad libitum feedings (food available $24 \mathrm{~h}$ ) and (๑), restricted feedings (food available 8-10 a.m.). * Values that are significantly less $(P<0.05)$ than the control group receiving ad libitum feedings. The statistical variations have been omitted to enhance visual clarity.

$0.0125)$ and amylase $(P<0.05)($ Fig. 3). Trypsinogen activity (Fig. 3 ) was not significantly altered as compared to controls. Lipase and amylase concentrations in malnourished animals were only $68 \%$ and $78 \%$, respectively, of that found in control animals. With subsequent ad libitum feedings, the activities of both amylase and lipase rose to levels comparable to controls at 7 and 14 days, respectively. With restricted feeding, the recovery of amylase was 


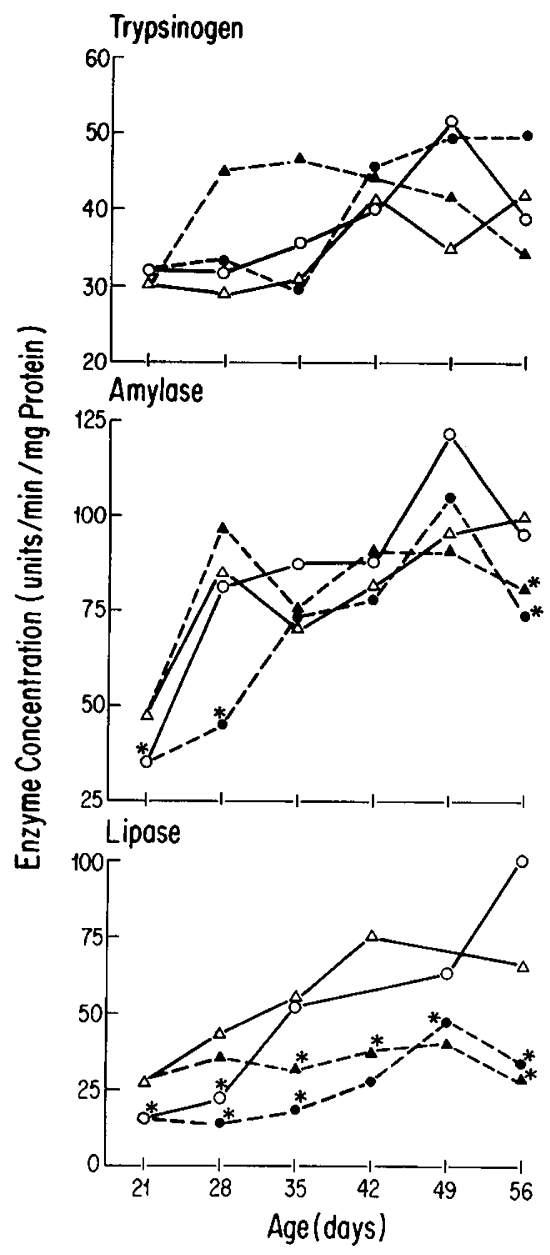

Fig. 3. Effect of postnatal malnutrition and subsequent nutritional rehabilitation by either ad libitum or restricted feedings on the concentrations of trypsinogen, amylase, and lipase. Symbols are the same as in Figure 2.

delayed by an additional 7 days i.e., to day 14 after weaning. More important, lipase activity remained depressed for the 56-day duration of the experiment. In all cases, restricted feeding resulted in lower concentrations of amylase and lipase compared to the corresponding groups fed ad libitum.

Total activities. The enzyme contents for each group reflected the weights of the organ; thus, graphic representation for each of the three enzymes studied (Fig. 4) were similar and paralleled the gains in weights of the organ (Fig. 2).

Total contents of all pancreatic enzymes in the malnourished animals at 21 days were diminished.

Amylase and trypsinogen contents attained levels comparable to controls by 7 days of ad libitum feedings whereas lipase required 14 days.

Both groups on restricted feedings continued to have significantly diminished enzyme content for the total duration of the experiment (Fig. 4).

\section{DISCUSSION}

During the fetal and immediate postnatal periods, food restriction may cause developmental changes of different organs. These changes can be reversible or permanent depending on its magnitude and duration. In animals, both intrauterine and early postnatal malnutrition have been shown to interfere with body and organ development $(1,9,14,17,30,32)$ but their reversibility has not been examined. For example, the degree of reversibility of morphologic alterations in the brain is dependent on the timing of the malnutrition. Irreversible changes are associated with early

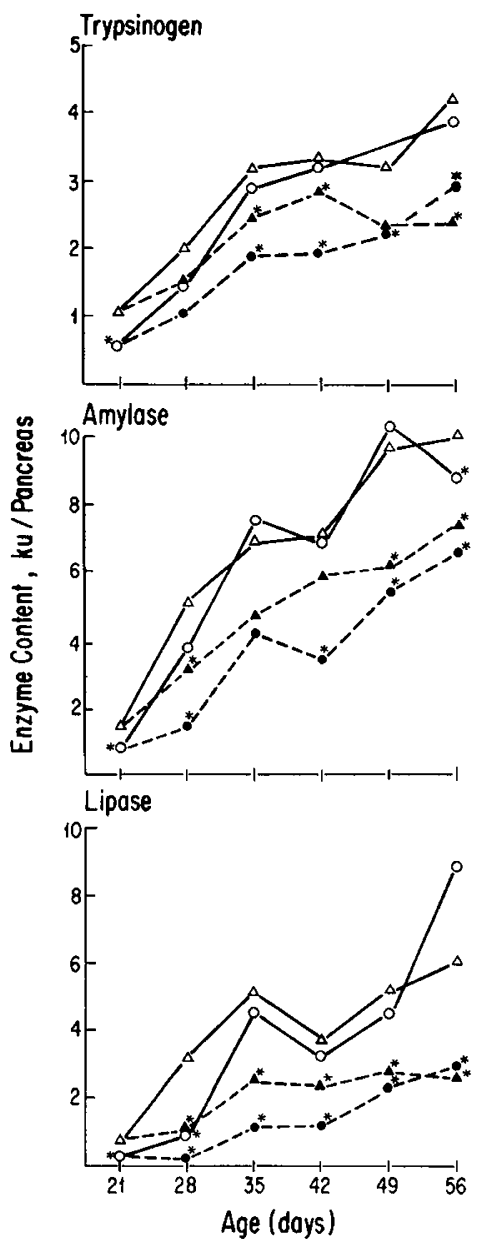

Fig. 4. Effect of postnatal malnutrition and subsequent nutritional rehabilitation by either ad libitum or restricted feedings on content of trypsinogen, amylase, and lipase. Symbols are the same as in Figure 2.

malnutrition, whereas later caloric restriction reversibly affects cellular growth (31).

The reversibility of the adverse effects of malnutrition on the pancreas, however, has been studied to only a limited extent. In children, severe malnutrition leads to a reduction in the secretion of the pancreatic enzymes $(2,5)$. The condition appears to be reversible after correction of dietary deficiency (2). Recovery of pancreatic enzyme concentrations to normal levels has also been shown in refeeding of fasted adult rats $(18,29)$. Reversal of changes in the developing pancreas after malnutrition and dietary rehabilitation, however, has not been studied previously. It is possible that during critical periods of ontogeny such as in the neonatal stage, a sustained deficiency in digestive enzyme activity might impair absorption and thus impede future organ development.

The present study showed that the pancreases of postnatally malnourished rats were greatly reduced in size and that the pancreatic contents of lipase, trypsinogen, and amylase were all reduced. The specific activities of these three enzymes were affected differently; lipase and amylase were decreased severely whereas trypsinogen was almost unchanged. This emphasizes our previous finding that concentrations of the various pancreatic enzymes are affected differently with the change of lipase most sensitive and trypsinogen most resistant to stress e.g., intrauterine growth retardation in rats (17), rotovirus type 3 infection (4), and leukemia induction in mice (3).

The present study showed that not all of these changes are reversible after nutritional rehabilitation and that the type of feeding regimen is an important determinant. Body growth appeared to be permanently retarded (for the duration of the exper- 
iment) with either ad libitum or restricted feedings; however, the retardation in growth was more evident with restricted feedings. The malnourished state was maintained as illustrated at 35 days after nutritional rehabilitation: body weights were still $46 \%$ below that of controls. These results are partially in agreement with those found by Leveille $(19,20)$ in that restricted feedings depressed the body weight of adolescent animals. Our findings reveal that weanling rats never show adaptive changes sufficient enough to allow for an equivalent gain in body weight as their counterparts fed ad libitum. This indicates a difference between weanling and adolescent rats in their response to restricted feeding. During the weaning period restricted feeding appeared to result in malnutrition because the control group that had no prior malnourishment also became lighter than the group that was fed ad libitum.

Our results show a complete reversibility of both contents and concentrations of pancreatic enzyme and as such is similar to that seen in fasted adult animals $(18,29)$. Restricted feedings seemed to maintain the malnourished state with regard to the depression in lipase activity and delayed recovery of amylase by an additional 7 days. This implies that adequate nutrition is required for recovery. It also suggests that lipase and amylase are more sensitive than trypsinogen to nutritional changes.

In summary, malnutrition induced in the immediate postnatal period leads to a permanent retardation in pancreatic and somatic growth. The induced pancreatic enzyme changes are apparently reversible with subsequent nutritional rehabilitation. Restricted feedings in the weanling period appears to prevent normal recovery of the pancreas.

\section{REFERENCES AND NOTES}

1. Aubert, R., Suquet, J. P., and Lemonnier, D.: Long-term morphological and metabolic effects of early under and overnutrition in mice. J. Nutr., 110:649 (1981).

2. Babezat, G. D. and Hauser, J. D. L.: The exocrine pancreas and protein caloric malnutrition. Pediatrics, $42: 77$ (1968).

3. Branski, D., Lebenthal, E., Freeman, A. I., Fisher, J. E., Hatch, T. F., and Krasner, J.: Methotrexate effect on pancreatic enzymes in leukemic mice. Dig. Dis. Sci., 24: 865 (1979).

4. Branski, D., Lebenthal, E., Faden, H. S., Hatch, T. F., and Krasner, J.: Reovirus type 3 infection in a suckling mouse: The effect on pancreatic structure and enzyme content. Pediatr. Res., 14: 8 (1980).

5. Davis, T. N. P.: The essential pathology of kwashiorkor. Lancet, 1: 317 (1974).

6. Erlanger, B. F., Kokowsky, N., and Cohen, W.: The preparation and properties of two new chromogenic substrates of trypsin. Arch. Biochem. Biophys., 95 . 271 (1961).

7. Fabry, P. and Kujalova, V.: Enhanced growth of small intestine in rats as a result of adaptation to intermittent starvation. Acta Anat., 43: 264 (1960).

8. Hadorn, B.: Assessment of Pancreatic Function. IN: Paediatric Gastroenterology, Ed. C. M. Anderson and V. Burke p. 663. (Oxford: Blackwell Scientific Publications, 1975).

9. Hatch, T. F., Lebenthal, E., Krasner, J., and Branski, D.: Effect of postnatal malnutrition on pancreatic zymogen enzymes in the rat. Am. J. Clin. Nutr. 32: 1224 (1979).

10. Hollified, G. and Parson, W.: Metabolic adaptations to a "stuff and starve" feeding program. I. Studies of adipose tissue and liver glycogen in rats limited to a short daily feeding period. J. Clin. Invest., 41(2): 245 (1962).

11. Hollified, G. and Parson, W.: Metabolic adaptations to a "stuff and starve" feeding program. II. Obesity and the persistence of adaptive changes in adipose tissue and liver occurring in rats limited to a short daily feeding period. J. Clin. Invest., 41: 250 (1962)

12. Jasper, H. and Brasel, J. A.: Rat liver DNA synthesis during the "catch-up" growth of varied nutritional rehabilitation. J. Nutr., 110: 2336 (1980).

13. Kaufman, M. A., Korsmo, H., and Olsen, W.: Circadian rhythm of intestinal sucrase activity in rats: Mechanism of enzyme change. J. Clin. Invest., 65: 1174 (1980).

14. Klotz, A. P., Murdock, A. L., and Suoboda, D. J.: The effect of protein deprivation on pancreatic function in young animals and on animals in utero. Dig. Dis. Sci., 17: 399 (1972).

15. Kujalova, V. and Fabry, P.: Role of corticoids in intestinal absorption of glucose in rats accustomed to intermittent starvation. Physiol. Bohemoslov, 7: 142 (1958).

16. Kujalova, V. and Fabry, P.: Intestinal absorption of glucose, fat and amino acids in rats adapted to intermittent starvation. Physiol. Bohemoslov., 9: 35 (1960).

17. Lebenthal, E., Nitzan, M., Chrzanowski, B. L., and Krantz, B.: The effect of reduced maternofetal blood flow on the development of fetal pancreatic acinar cells and enzymes. Pediatr. Res., 14: 1356 (1980).

18. Lee, P. C., Brooks, S., and Lebenthal, E.: Effects of fasting and feeding on pancreatic enzyme and secretagogue responsiveness in rats. Am. J. Physiol., 242: G215 (1982).

19. Leveille, G. A.: Adipose tissue metabolism: Influence of periodicity of eating and diet composition. Fed. Proc., 29(3): 1294 (1970).

20. Leveille, G. A.: Long term effects of meal eating on lipogenesis, enzyme activity, and longevity in the rat. J. Nutr., 102: 549 (1972).

21. Leveille, G. A. and Hanson, R. W.: Adaptive changes in enzyme activity and metabolic pathways in adipose tissue from meal-fed rats. J. Lipid Res., 7: 46 (1966).

22. Lowry, O. H., Rosebrough, N. J., Farr, A. L., and Randall, R. J.: Protein measurement with the folin phenol reagent. J. Biol. Chem., 193: 265 (1951).

23. Nordstrom, C. and Dahlquist, A.: Rat enterokinase: The effect of ions and the localization in the intestine. Biochim. Biophys. Acta, 242: 209 (1971).

24. Pose, G., Fabry, P., and Ketz, H. A.: Aktivität der Pankreasenzyme in Abhängigkeit von der Frequenz der Nährungsaufnahme bei ratten. Acta Biol. Med. Germ., 20: 253 (1968).

25. Seavey, R. L., Hagashi, S., and Berk, J. E.: A new microsaccharogenic method for serum amylase determination. Tech. Bull. Regist. Med. Techn., 36: 252 (1966).

26. Stevenson, N. R. and Fierstein, J. S.: Circadian rhythms of intestinal sucrase and glucose transport: cued by time of feeding. Am. J. Physiol., 230: 731 (1976).

27. Sutherland, E., Covi, C. F., Haynes, R., and Olsen, N. S.: Purification of the hyperglycemic-glycogenolytic factor from insulin and from gastric mucosa. J. Biol. Chem., 180: 825 (1949).

28. Tepperman, J. and Tepperman, H. M.: Effects of antecedent food intake on hepatic lipogenesis. Am. J. Physiol., 193: 55 (1958).

29. Webster, P. D., Sungh, M., Tucker, P. C., and Balck, O.: Effects of fasting and feeding on the pancreas. Gastroenterology, 62: 600 (1972)

30. Weisblum, B., Herman, L., and Fitzgerald, J.: Changes in pancreatic acinar cells during protein deprivation. J. Cell. Biol., 12: 313 (1962).

31. Winick, $M$. and Noble, A.: Cellular response in rats during malnutrition at various ages. J. Nutr., 89: 300 (1966).

32. Younoszai, M. K., Swanson, J. D. Jr., and Ranshaw, J.: Intestinal disaccharidases in newborn and mother rats: Effect of dietary protein deficiency during pregnancy. Am. J. Clin. Nutr., 31: 931 (1978).

33. Requests for reprints should be addressed to: Dr. Emanuel Lebenthal, Division of Gastroenterology and Nutrition, Children's Hospital of Buffalo, 219 Bryant Street, Buffalo, New York 14222

34. This research was supported in part by NIH grant \#12586, Bio-Medical Research Support Grant \#RR-05493-18, and by the Ralph Hochstetter Medical Research Advance in honor of Dr. Henry C. and Bertha H. Buswell, State University of New York at Buffalo.

35. Received for publication August 3, 1982.

36. Accepted for publication February 14, 1983. 